\title{
Propionibacteria induce apoptosis of colorectal carcinoma cells via short-chain fatty acids acting on mitochondria
}

\author{
G Jan ${ }^{1}$, A-S Belzacq ${ }^{2}$, D Haouzi ${ }^{3}$, A Rouault ${ }^{1}$, D Métivier ${ }^{3}$, \\ G Kroemer ${ }^{3}$ and $C$ Brenner ${ }^{\star, 2,3}$ \\ 1 Institut National de la Recherche Agronomique, UR 121, Laboratoire de \\ Recherches de Technologie Laitière, 35042 Rennes Cedex, France \\ ${ }^{2}$ Centre National de la Recherche Scientifique, UMR 6022, Université de \\ Technologie de Compiègne, 60205, Compiègne, France \\ ${ }^{3}$ Centre National de la Recherche Scientifique, UMR 1599, Institut Gustave \\ Roussy, 39 rue Camille Desmoulins, 94805 Villejuif, France \\ * Corresponding author: C Brenner, Centre National de la Recherche \\ Scientifique, UMR 6022, Université de Technologie de Compiègne, Royallieu, \\ BP20529, 60205, Compiègne, France. Tel: 33-3-44-23-44-16; \\ Fax: 33-3-44-20-39-10; E-mail: catherine.brenner@utc.fr
}

Received 9.5.01; revised 26.7.01; accepted 3.8.01

Edited by S Martin

\begin{abstract}
The genus Propionibacterium is composed of dairy and cutaneous bacteria which produce short-chain fatty acids (SCFA), mainly propionate and acetate, by fermentation. Here, we show that $P$. acidipropioniciand freudenreichii, two species which can survive in the human intestine, can kill two human colorectal carcinoma cell lines by apoptosis. Propionate and acetate were identified as the major cytotoxic components secreted by the bacteria. Bacterial culture supernatants as well as pure SCFA induced typical signs of apoptosis including a loss of mitochondrial transmembrane potential, the generation of reactive oxygen species, caspase-3 processing, and nuclear chromatin condensation. The oncoprotein $\mathrm{Bcl}-2$, which is known to prevent apoptosis via mitochondrial effects, and the cytomegalovirus-encoded protein vMIA, which inhibits apoptosis and interacts with the mitochondrial adenine nucleotide translocator (ANT), both inhibited cell death induced by propionibacterial SCFA, suggesting that mitochondria and ANT are involved in the cell death pathway. Accordingly, propionate and acetate induced mitochondrial swelling when added to purified mitochondria in vitro. Moreover, they specifically permeabi-lize proteoliposomes containing ANT, indicating that ANT can be a critical target in SCFA-induced apoptosis. We suggest that propionibacteria could constitute probiotics efficient in digestive cancer prophylaxis via their ability to produce apoptosis-inducing SCFA.

Cell Death and Differentiation(2002) 9, 179 - 188. DOI: 10.1038/sj/ cdd/4400935
\end{abstract}

Keywords: Adenine nucleotide translocator; apoptosis; cancer; mitochondria; probiotic; propionibacteria; short-chain fatty acid

Abbreviations: ANT, adenine nucleotide translocator; Atr., atractyloside; SN, bacterial DMEM supernatant; Co., control; 4-
MUP, 4-methylumbelliferyl phosphate; 4-MU, 4-methylumbelliferone; $\Delta \Psi \mathrm{m}$, mitochondrial transmembrane potential; csA, cyclosporin $\mathrm{A} ; \mathrm{DiOC}_{(6)} 3,3-3^{\prime}$-dihexyloxacarbocyanineiodide; $\mathrm{HE}$, hydroethidine; PTPC, permeability transition pore complex; PBR, peripheral benzodiazepin receptor; RT, room temperature; ROS, reactive oxygen species; SCFA, short-chain fatty acids; SDSPAGE, sodium dodecyl sulfate polyacrylamide gel electrophoresis; VDAC, voltage-dependent anion channel.

\section{Introduction}

Oncogenesis is determined by a combination of genetic factors and environmental causes including radiation, chemical carcinogens and diet. Indeed, the role of diet in cancer development is strongly supported by epidemiological studies, in particular in the case of cancers of the digestive tract. ${ }^{1}$ The major impact of eating habits on the prevalence of colon cancers has triggered efforts to design an optimal diet and/or to create food supplements specifically reducing the risk of cancer. Probiotics are nonpathogenic micro-organisms that, when ingested, exert a positive influence on the health or physiology of the host. ${ }^{2}$ They can influence intestinal physiology either directly or indirectly through regulation of the endogenous microflora. Among different dietary bacteria, the propionibacteria form a genus, which is found in specific dairy products such as Swiss-type cheese. The metabolism of propionibacteria relies on the anaerobic conversion of carbohydrates and lactic acid to short-chain fatty acids (SCFA), in particular propionate and acetate. ${ }^{3}$ It has been previously shown that the SCFA butyrate (which is generated by endogenous bacteria not belonging to the genus Propionibacterium), ${ }^{4,5}$ induces apoptosis in colon cancer cells but not in normal cells. $^{5-8}$ Thus, with the aim to define a new cancer prophylaxis based on dietary probiotics supplementation, we investigated the cytotoxic potential of propionibacteria on human colon cancer cells.

In the course of apoptosis, mitochondrial alterations consist primarily in an increase in mitochondrial membrane permeability, due at least in part, to the opening of the permeability transition pore complex (PTPC). The PTPC is a protein complex located at the contact site between the two mitochondrial membranes. ${ }^{9}$ It is composed of several proteins including hexokinase (cytosol), porin, also called voltage-dependent anion channel (VDAC, a major protein in the outer membrane), peripheral benzodiazepin receptor (PBR, outer membrane), ANT (a major protein in the inner membrane) and cyclophilin D (matrix). Recently, it has been shown that PTPC is involved in the apoptotic process induced by a variety of pro-apoptotic signals such as proapoptotic Bcl-2-family members, ${ }^{10,11}$ viral proteins, ${ }^{12,13}$ chemotherapeutic agents ${ }^{14,15,16}$ and lipids such as palmitate ${ }^{17}$ and ganglioside GD3. ${ }^{18}$ Upon apoptosis induction, 
the PTPC protein ANT may form a large non-specific pore, allowing for the diffusion of molecules up to $1500 \mathrm{Da}$ on the inner mitochondrial membrane. This leads to the dissipation of the inner transmembrane potential $(\Delta \Psi \mathrm{m})$, enhanced generation of reactive oxygen species (ROS), colloidosmotic swelling of the mitochondrial matrix, and permeabilization of the outer membrane with consecutive release of apoptogenic proteins from the intermembrane space to the cytoplasm. ${ }^{19,20}$ All these events are prevented by oncoproteins from Bcl-2 family, which have been shown to interact with PTPC components, in particular $\mathrm{ANT}^{10,11,21}$ and VDAC. $^{22}$

Of note, most anti-cancer agents, albeit cytotoxic, have no direct effects on mitochondria. Rather, they elicit signal transduction pathways which indirectly affect mitochondria. Prominent examples include the p53-induced upregulation of proteins acting on mitochondria (e.g. the $\mathrm{Bcl}-2$ antagonist Bax, p53-Ap1, proline oxidase $)^{23}$ as well as the generation of second messengers including $\mathrm{Ca}^{2+}$, ganglioside GD3, $\mathrm{NO}$, and ROS. ${ }^{15}$ Recently, it has been discovered that a number of experimental chemotherapeutic agents directly affect mitochondria. This applies to betulinic acid, ${ }^{24,25}$ lonidamine, ${ }^{26}$ arsenite, ${ }^{27}$ 6[3-adamantyl-4-hydroxyphenyl]2-naphthalene carboxylic acid (CD437), ${ }^{27}$ 2-chloro-2'deoxyadenosine, 2-chloro-2'-arafluorodeoxyadenosine, ${ }^{29}$ verteporfin ${ }^{16}$ and MT-21. ${ }^{30}$

The aim of the present study was to determine whether propionibacteria could kill colon cancer cells. For this purpose, we chose three propionibacteria strains selected for their tolerance toward digestive stresses, ${ }^{31,32}$ namely Propionibacterium acidipropionici strain CNRZ80, $P$. freudenreichii subsp. freudenreichii strain ITG18, and $P$. freudenreichii subsp. shermanii strain SI41, SI41 being a commercially available probiotic. Our data demonstrate that these strains kill human cancer cell lines, such as HeLa, HT29 and Caco2 cells, apparently via SCFA. We have investigated the mechanism whereby SCFA induce apoptosis and provide evidence that they directly act on mitochondria to permeabilize their membranes.
A

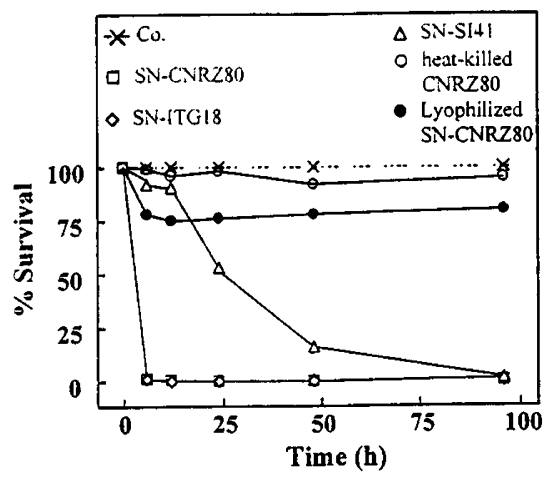

B

\begin{tabular}{lccccc}
\hline $\begin{array}{l}\text { Bacteria DMEM } \\
\text { Supernatant }\end{array}$ & $\begin{array}{c}\text { Propionic acid } \\
(\mathrm{mM})\end{array}$ & $\begin{array}{c}\text { Acetic acid } \\
(\mathrm{mM})\end{array}$ & $\mathrm{pH}$ & $\begin{array}{l}\mathrm{t}_{1 / 2} \\
(\mathrm{~h})\end{array}$ \\
\hline SN-CNRZ80 & 39.5 & 16.0 & 5.5 & 3 \\
SN-ITG18 & 36.3 & 12.5 & 5.6 & 3 \\
SN-SI41 & 26.1 & 9.3 & 6.4 & 26 \\
$\begin{array}{l}\text { Lyophilized } \\
\text { SN-CNRZ80 }\end{array}$ & 6.2 & 1.7 & 5.5 & $>100$ \\
\hline
\end{tabular}

C

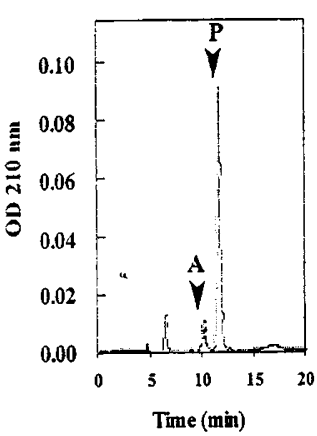

SN-ITG18

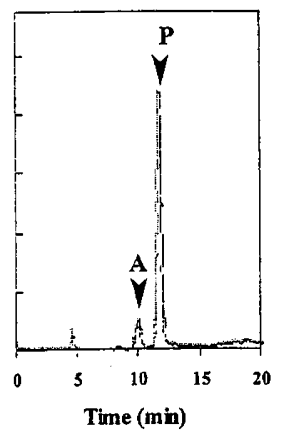

SN-SI41

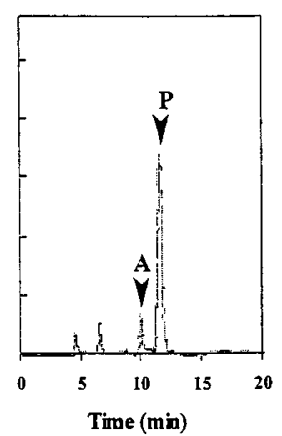

Lyophilized SN-CNRZ80

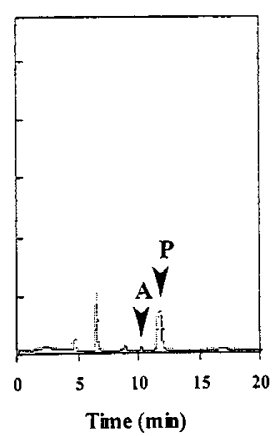

Figure 1 SCFA mediate propionibacteria-induced cell death. (A) Effects of propionibacteria on HT29 colon cancer cells. $1.10^{6}$ HT29 cells were co-cultured with supernatants of different strains of propionibacteria, namely $P$. acidipropionici CNRZ80, $P$. freudenreichii subsp. freudenreichii ITG18, or $P$. freudenreichii subsp.shermanii SI41. As controls, cell cultures were inoculated with heat-killed CNRZ80 strain or with a lyophilized supernatant of strain CNRZ80. Cell viability was determined after different periods of culture. This experiment has been reproduced three times. (B) Chromatographic analysis of SCFA in DMEM culture supernatants (SN). DMEM was inoculated with CNRZ80, ITG18 or SI41 strain. After growth, supernatants were prepared by centrifugation prior to chromatographic quantification of acetate $(A)$ and propionate $(P)$ in comparison with molecular standards, as described in Material and Methods. As a control, SN-CNRZ80 was lyophilized extensively and reconstituted before analysis in the same conditions. (C) Composition and activity of propionibacterial supernatants. The concentration of short-chain fatty acids was analysed by HPLC chromatography as in B, and the time course leading to $50 \%$ of HT29 cell death ( $\mathrm{t}_{1 / 2}$ ) was determined as in A 


\section{Results}

\section{Propionibacteria kill colorectal cancer cell lines}

To investigate the cytotoxic potential of different strains and species of diary propionibacteria, we co-cultured HT29 colorectal carcinoma cells with Propionibacterium acidipropionici strain CNRZ80, $P$. freudenreichii subsp. freudenreichii strain ITG18, and $P$. freudenreichii subsp. shermanii strain SI41. All these strains caused cell killing (not shown). The cytocidal effect of propionibacteria could not be attributed to bacterial invasion of host cells (not shown) nor to surface interactions, since heat-inactivation abolished cell killing. Rather, the supernatants (SN) of propionibacteria sufficed to kill HT29 colon carcinoma cells (Figure 1A), Caco 2 cells (not shown) and Jurkat lymphoma cells (not shown) suggesting that cancer cell killing was due to the presence of soluble factors contained in the medium. As a control of bacterial genus specificity, the Escherichia coli SN effect was also evaluated. Accordingly, the E.coli SN did not induce HT29 cell killing. The cytotoxic effects were fast : half-maximal killing by $\mathrm{SN}$ derived from CNRZ80 or ITG18 occurred within $3 \mathrm{~h}$ and that of SN derived from SI41 occurred within $24 \mathrm{~h}$ (Figure 1A). Lyophilization abolished the cytotoxic effect of $\mathrm{SN}$ from CNRZ80 (Figure 1A), suggesting that the lethal compound contained in the SN was volatile. We performed HPLC analyses of the SN to detect the presence of candidate volatile molecules. Acetate and propionate were identified as the major SCFA in SN from CNRZ80, ITG18 and SI41 (Figure 1C). Both fatty acids were partially eliminated by lyophilization of SN CNRZ80 (Figure 1C).

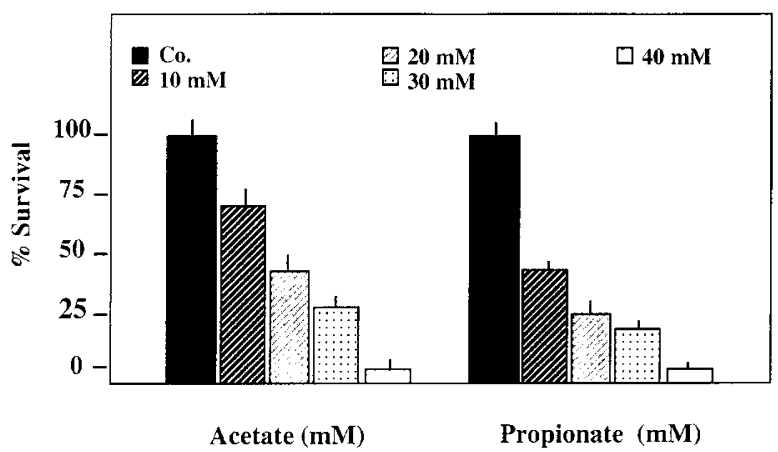

Figure 2 Effects of pure acetate and propionate on the viability of HT29 cells. $1.10^{6}$ cells were left untreated (Co.) or were treated with various concentrations of propionate or acetate. The percentage of surviving cells was determined after $48 \mathrm{~h}$ of culture by Trypan blue exclusion. Results are mean values of three independent experiments \pm S.E.M.
$\mathbf{A}$
$0^{\circ}$

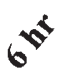
9<smiles>[CH]</smiles>
5
Cleaved caspase 3 (p17)

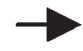
cones

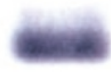
Caco2

Cleaved caspase 3 (p17)
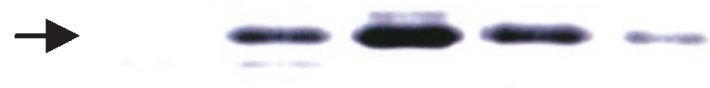

HT29

B

Co.
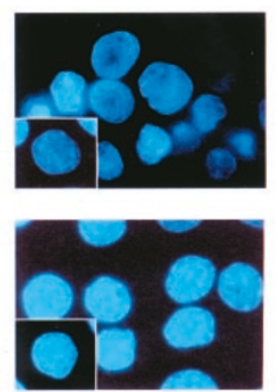

SN ITG18
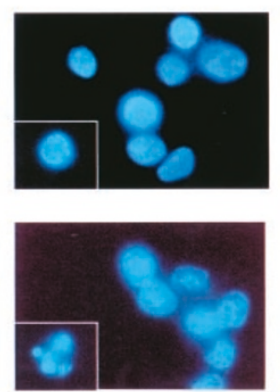

SN CNRZ80
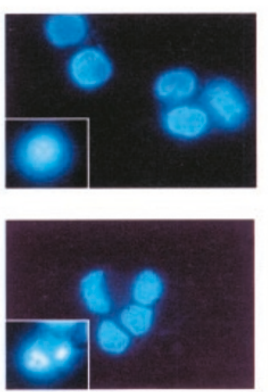

Propionate/ Acetate

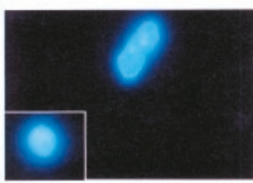

Caco2

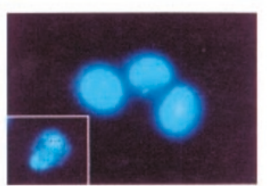

HT29

Figure 3 SCFA produced by propionibacteria induce apoptosis in HT29 and Caco 2 cells. (A) SCFA-induced caspase 3 processing. Cells were treated by SCFA in DMEM. At different times, $5 \times 10^{6}$ cells were subjected to SDS-PAGE, and the cleaved caspase 3 (p17) subunit p20 was detected by immunoblot. (B) SCFA induced nuclear condensation. Cells were cultured (Co.) or treated for 24 or $48 \mathrm{~h}$ (inserts) in the presence of SN-CNRZ80, SN-ITG18 or sodium propionate and acetate, followed by Hoechst 33324 staining and fluorescence microscopy 
A
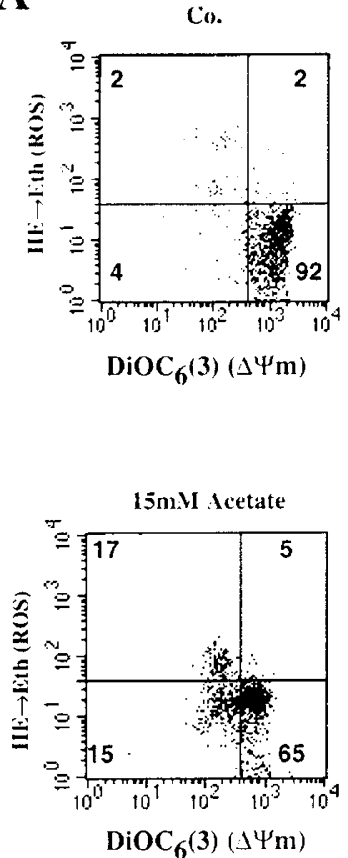

C

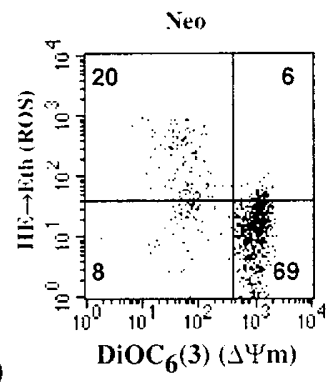

S. ITIS

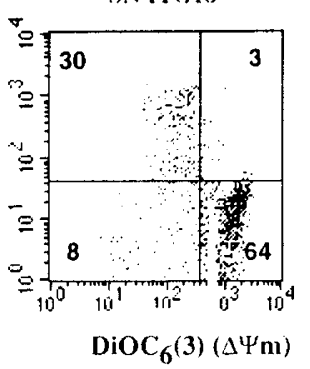

$15 \mathrm{mM}$ Propionate

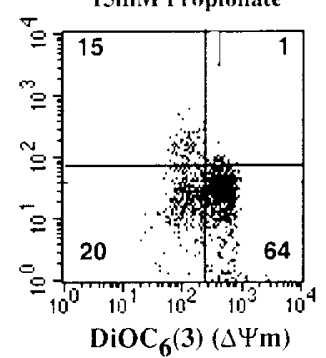

Bcl-2

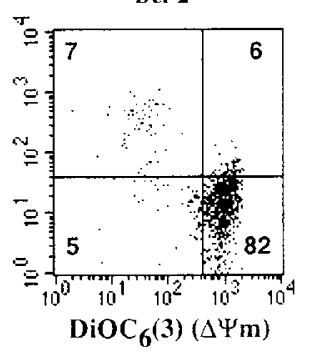

SN (NRZ81)

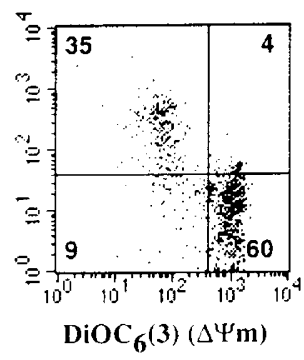

B

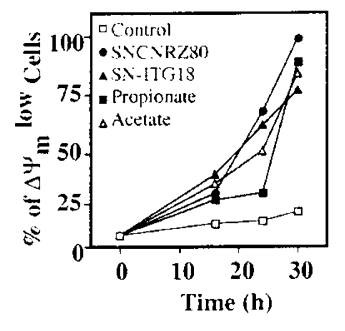

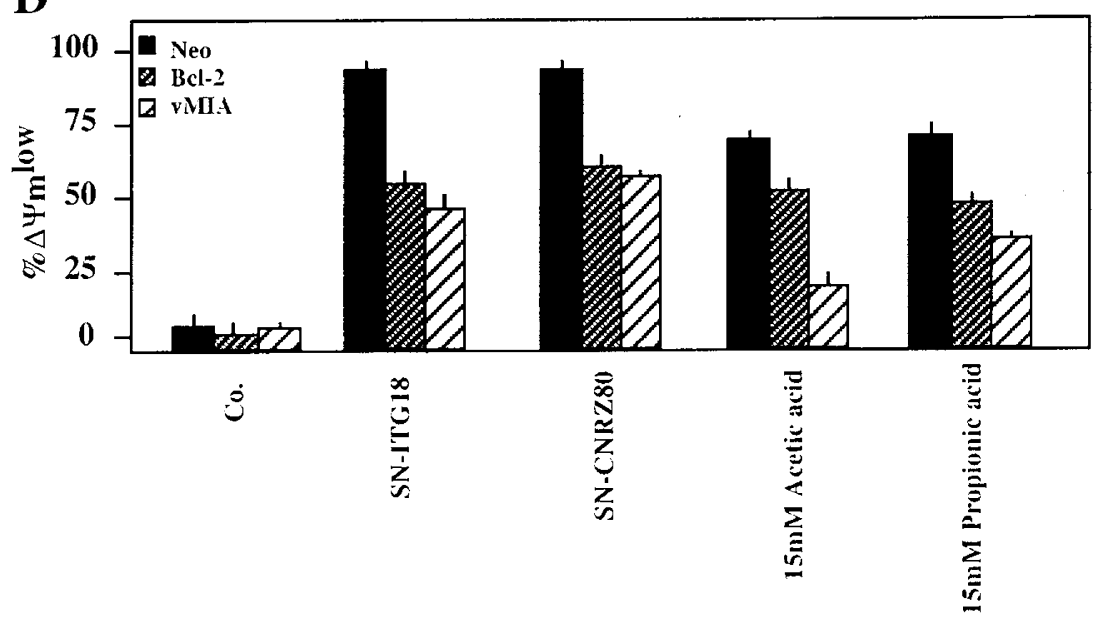

Figure 4 Effect of propionibacterial supernatants and SCFA on apoptosis-associated mitochondrial parameters. (A) Determination of the dissipation of the inner membrane potential $(\Delta \Psi \mathrm{m})$ and the generation of reactive oxygen species (ROS). HT29 cells were cultured for $16 \mathrm{~h}$ with SN-CNRZ80, SN-ITG18, propionate or acetate, followed by staining with $\mathrm{DiOC}_{(6)} 3$ and $\mathrm{HE}$ and cytofluorimetric analysis. Numbers indicate the percentage of cells found in each quadrant. (B) Kinetic analysis of the $\Delta \Psi \mathrm{m}$ dissipation. $\Delta \Psi \mathrm{m}$ was measured at $0,16,24$ and $36 \mathrm{~h}$ of cell treatment by DiOC ${ }_{(6)} 3$ staining as in $\mathbf{A}$. (C) Inhibition of apoptosis by Bcl-2 and VMIA. HeLa cells transfected with the vector only ( $\mathrm{Neo}$ ), the human $\mathrm{Bcl}-2$ gene or the cytomegalovirus-derived vMIA gene, were treated with $15 \mathrm{mM}$ acetate for $16 \mathrm{~h}$, followed by $\mathrm{DiOC}_{(6)} 3 / \mathrm{HE}$ staining and cytofluorometric analysis as in $\mathbf{A}$. (D) Comparison of the effects of propionibacterial supernatants and pure SCFA on HeLa cell expressing the Neo resistance gene only, Bcl-2 or VMIA. Data are representative of two experiments 
No butyrate formation could be detected under these conditions. The ratios propionate/acetate ranged between 2.5 and 2.9, as expected for propionibacteria, which generally produce more propionate than acetate. ${ }^{3}$ The SN-CNRZ80 contained more acetate $(16 \mathrm{mM})$ and propionate $(39.5 \mathrm{mM})$ than the SN-ITG18 (12.5 and $36.3 \mathrm{mM}$ respectively) and also more than the SN-SI41 (9.3 and $26.1 \mathrm{mM}$ ) (Figure 1B), correlating with the cytotoxic potential of the supernatants (Figure 1C). We then tested the cytotoxicity of propionate and acetate and found that these compounds killed HT-29 cells with an ED $E_{50}$ of 11 and $20 \mathrm{mM}$ respectively (Figure 2). Taken together, these data indicate that propionibacteria efficiently kill colon carcinoma cells, at least in part, due to their specific property to produce two SCFA, propionate and acetate.

\section{Propionibacterial SCFA induce apoptosis of colon carcinoma cells}

Apoptosis proceeds via a series of biochemical events different from those occurring during necrosis. For instance, apoptosis but not necrosis usually involves the activation of caspases and nuclear alterations such as chromatin condensation. To characterize the propionibacterial SCFAinduced cell death, the processing of caspase 3 was analyzed by SDS-PAGE and immunoblotting of SN and SCFA-treated HT29 and $\mathrm{CacO} 2$ cells (Figure 3A). The bacterial SN-ITG18 and -CNRZ80 (data not shown), as well as the mixture of propionate and acetate in a [2:1] molar ratio, induced the cleavage of pro-caspase 3 and the generation of the active form of caspase 3 , the subunit p20 (Figure 3A). In addition, SN-treated HT29 and Caco2 cells were labeled with the Hoechst 33324 dye and analyzed for chromatin condensation by fluorescence microscopy (Figure $3 B)$. In comparison to untreated cells, the nuclei of SNCNRZ80, SN-ITG18, propionate and acetate-treated cells shrank, chromatin condensed, and finally nuclei fragmented into apoptotic bodies (Figure 3B). In conclusion, the mode of death triggered by propionibacteria is apoptosis rather than necrosis.

\section{Propionibacterial SCFA-induced apoptosis involves mitochondrial changes which are antagonized by Bcl-2 and an ANT-targeted viral protein}

With the goal of determining whether the mechanisms of propionibacterial SCFA-induced cell death involve mitochondria, we measured two critical mitochondrial parameters, the inner membrane potential, $\Delta \Psi \mathrm{m}$, and the generation of ROS, using a combination of two fluorescent probes, $\mathrm{DiOC}_{(6)} 3$ (which is $\Delta \Psi \mathrm{m}$-sensitive) and $\mathrm{HE}$ (which detects ROS). As shown in Figure 4A, untreated cells (Co.) exhibited a high $\triangle \Psi \mathrm{m}$ and a low $\mathrm{HE}$ fluorescence. SN from ITG18 and CNRZ80, as well as acetate or propionate, induced a reduction in the $\mathrm{DiOC}_{(6)} 3$-dependent fluorescence and an increase in the HE-dependent fluorescence, indicating an increase in the mitochondrial inner membrane permeability and an enhanced generation of ROS (Figure
4A). The kinetics of the $\Delta \Psi \mathrm{m}$ dissipation elicited by propionibacterial $\mathrm{SN}$, acetate or propionate were comparable (Figure 4B). Recently, VMIA, a protein encoded by human cytomegalovirus, has been demonstrated to prevent apoptosis, presumably via an interaction with ANT. ${ }^{33} \mathrm{HeLa}$ cell lines stably transfected with a control vector only (Neo), $\mathrm{Bcl}-2$, or VMIA were treated with acetate, followed by determination of the $\Delta \Psi \mathrm{m}$ and ROS generation. Bcl-2 and VMIA conferred a significant protection against the mitochondrial effects of acetate (Figure $4 \mathrm{C}$ ), propionate, and the SN or ITG18 and CNRZ80 (Figure 4D). This indicates that the mitochondrial effects of propionibacterial SCFA are regulated by $\mathrm{Bcl}-2$ and $\mathrm{VMIA}$.

\section{Propionibacterial SCFA act on purified mitochondria, as well as on ANT reconstituted into proteoliposomes}

When isolated mouse liver mitochondria were treated with $100 \mu \mathrm{M} \mathrm{Ca2+}$, they underwent large amplitude swelling due to the opening of the PTPC pore, a process which could be inhibited by pre-treatment with cyclosporin $A(C s A)$, a ligand of the mitochondrial matrix protein cyclophilin $D$, one of the PTPC constituents (Figure 5). Similarly, the SN of ITG18 or CNRZ80, as well as SCFA, induced the swelling of mitochondria in a dose-dependent manner (Figure 5). These effects were largely inhibited by CsA, suggesting that opening of the PTPC rather than non-specific membrane destabilization by fatty acids accounts for membrane permeabilization. To identify the SCFA target within the PTPC, we investigated the effects of SN and SCFA on phosphatidylcholine/cardiolipin liposomes containing ANT or not (plain liposomes). Briefly, ANT was purified from rat heart mitochondria and reconstituted in liposomes as detailed in Material and Methods. Then, as an indication of ANT pore opening (Belzacq et al., 2001), ${ }^{16}$ we measured the release of a fluorescent probe, 4-MUP, from the liposomal lumen. Propionibacterium-produced SCFA were devoid of any permeabilizing effect on plain liposomes (not shown), yet had a potent 4-MUP-releasing effect on ANTproteoliposomes (Figure 6). The SCFA effects were inhibited by the two natural ligands of ANT, ATP and ADP. In conclusion, ANT could be the target, or one of the targets, of SCFA-mediated mitochondrial membrane permeabilization.

\section{Discussion}

In this study, we report that different strains and species of propionibacteria kill cancer cells via the metabolic production of two SCFA, propionate and acetate. This notion is based on the evidence that (i) SN of propionibacteria were as cytotoxic as live strains (Figure 1A); (ii) the cytotoxic effect of various propionibacterial strains correlated with the amount of SCFA they produce (Figure 1B,C), (iii) removal of propionate and acetate by lyophilization from the $\mathrm{SN}$ abolished their cytotoxic activity (Figure 1B,C); and (iv) all subcellular and molecular effects mediated by SN of propionibacteria could be mimicked by propionate and acetate alone or in combination (Figures 
A

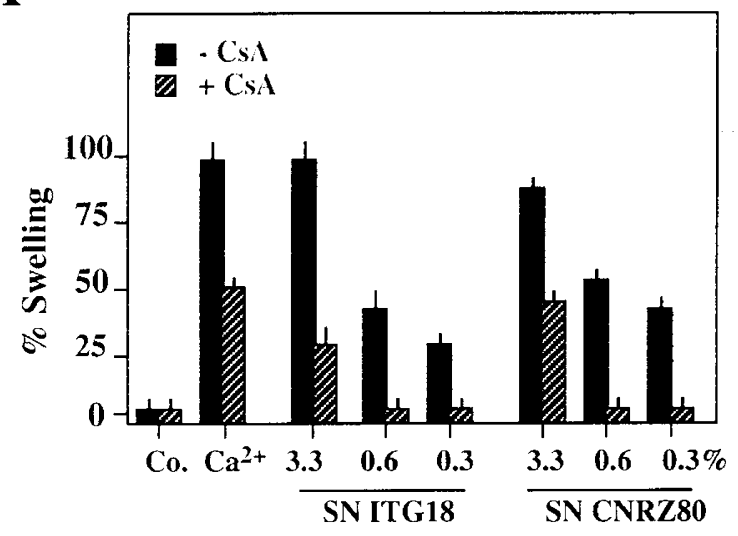

B

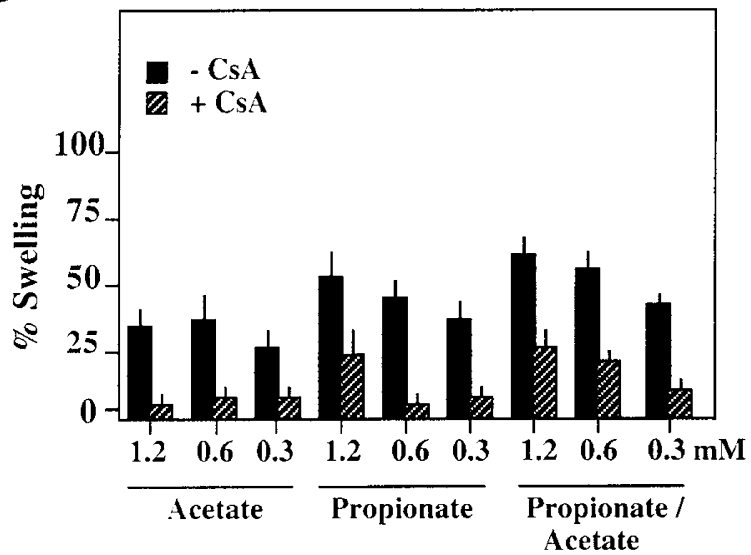

Figure 5 Propionibacterial SCFA trigger large amplitude swelling in isolated mitochondria (A) Swelling induced by SN of ITG18 or CNRZ80. Mouse liver mitochondria were isolated on a Percoll ${ }^{\circledR}$ gradient, and aliquots $(110 \mu \mathrm{g}$ proteins $/ \mathrm{ml}$ ) were treated with SN of ITG18, CNRZ80 or $100 \mu \mathrm{M}$ calcium. Absorbance at $540 \mathrm{~mm}$ was recorded for $20 \mathrm{~min} .100 \%$ swelling represents the maximal swelling obtained with $100 \mu \mathrm{M}$ calcium. Optionally, CsA was added $5 \mathrm{~min}$ before the indicated agents. (B) Swelling of mitochondria induced by SCFA. The same procedure as described in (A) was applied to various doses of acetate, propionate, or a mixture of both acids in a [2:1] molar ratio. Values represent mean percentages \pm S.E.M. from three independent experiments

$2-6)$. The $\mathrm{ED}_{50}$ of propionate and acetate were found to be relatively high, around $15 \mathrm{mM}$. Nonetheless, these two SCFA do not kill cells in a non-specific fashion, based on the finding that they induce apoptosis rather than necrosis (Figure 3), and that their cytotoxic effects were antagonized by overexpression of two apoptosis inhibitors, Bcl-2 and VMIA (Figure 4C).

What is then the mechanism of apoptosis induction by propionibacterial SCFA? In many models, apoptosis can be divided in three phases, an initiation phase (pre-mitochondrial phase), a decision phase (mitochondrial phase) and a degradation phase (cytoplasmic, nuclear and membranous alterations. ${ }^{19,20}$ As for butyrate 7,34 and the long-chain fatty acid, palmitate, ${ }^{17}$ propionate and acetate-induced apoptosis occurred via the stereotyped biochemical events that belong to the three phases model, including mitochondrial alterations, caspase activation and nuclear degradation.

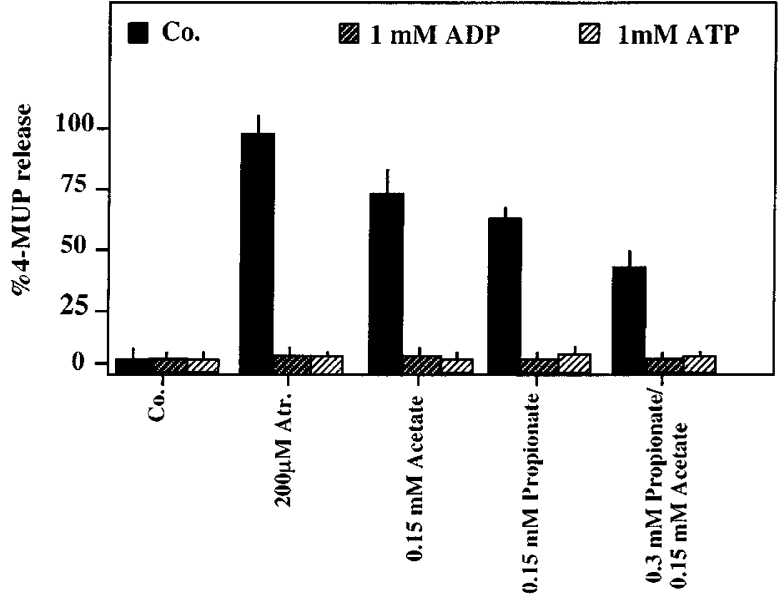

Figure 6 SCFA effects on ANT-containing liposomes. 4-MUP was encapsulated into ANT liposomes. Then, ANT liposomes were incubated with $1 \mathrm{mM}$ ADP, $1 \mathrm{mM}$ ATP or liposome buffer only (Co.) for $30 \mathrm{~min}$. Atractyloside or the indicated SCFA were added for another hour at RT. The percentage of 4MUP release (indicative of membrane permeabilization) was determined as described in Material and Methods. Values represent mean percentages \pm S.E.M. from three independent experiments

More precisely, the subcellular events in Caco2 and HT29 cells treated with propionibacterial SCFA were, at least, $\Delta \Psi \mathrm{m}$ dissipation, ROS generation, caspase 3 processing, chromatin condensation and nuclear fragmentation (Figures $3,4)$. Our observations that mitochondrial inhibitors of apoptosis $\mathrm{BCl}-2^{1,11}$ and $\mathrm{VMIA}^{33}$ prevent partially propionibacterial SCFA-induced cell killing suggest that mitochondria play a critical role in the death process (Figure $4 \mathrm{C}$ ). However, additional time course experiments would be necessary to determine if mitochondria support an initiator role or not in SCFA-induced apoptosis.

Surprisingly, we found that propionibacterial SCFA induced CsA-inhibitable swelling of isolated mitochondria (Figure 5). Since CsA reportedly inhibits the PTPC, this argues for the ability of SCFA to act directly on mitochondria and, more precisely on the PTPC. Stimulated by the fact that VMIA selectively interacts with ANT, ${ }^{33}$ one of the PTPC components, and that VMIA inhibits propionibacterial SCFA-triggered apoptosis (Figure 4C), we investigated the possibility that SCFA might directly act on ANT. Propionibacterial SCFA permeabilized ANT liposomes but failed to act on protein-free liposomes (Figure 6). Apparently, this effect involves a conformational or functional change of ANT, because it is inhibited by ATP and ADP (Figure 6). The functional SCFA-ANT interaction is reminiscent of that observed for palmitate and similar saturated long-chain fatty acids, which have previously been reported to bind to $\mathrm{ANT}^{35,36}$ and to induce PTPC opening. ${ }^{37,38}$ Of note, the SCFA effects obtained on purified mitochondria and ANT liposomes were observed at much lower doses, around 150-300 $\mu \mathrm{M}$ (Figures 5,6), than the doses required for cell killing. This may be due to the fact that the plasma membrane is not permeable to the anionic form of propionibacterial SCFA $\mathrm{A}^{39}$ and that the anionic form predominates at neutral $\mathrm{pH}$. 
Having elucidated the pro-apoptotic mode of action of some strains of propionibacteria, it is tempting to speculate on the medical and therapeutic applications of propionibacterial SCFA. $P$. acnes, a human skin pathogen, has been previously shown to induce apoptosis of various cells indirectly via the stimulation of $\operatorname{TNF}_{\alpha}$ synthesis by immune cells. ${ }^{40}$ In sharp contrast, we observed that three dairy strains of Propionibacterium induced apoptosis directly, in HT29, Caco2, or HeLa cells, without the need of accessory cells (Figure 1,3,4), apparently via SCFA. In humans, after supplementation, dairy propionibacteria survive to the digestive stress (mediated by acidic $\mathrm{pH}$, bile salts or hydrolases) at concentrations compatible with potential probiotic activities (fecal concentration $>10^{6} \mathrm{CFU} / \mathrm{g}^{34}$ ). In particular, the $P$. freudenreichii strain SI41, has been shown to survive the transit through the human digestive tract, ${ }^{41}$ which is linked to highly efficient adaptive response to digestive stresses. ${ }^{31,32}$ Indeed, in a recent study, ${ }^{32}$ propionibacteria (strain SI41) were ingested by seven healthy volunteers at doses ranging from $5.10^{9}$ (equivalent to $10 \mathrm{~g}$ of cheese) to $5.10^{10}$ (equivalent to $100 \mathrm{~g}$ of cheese). In the optimal protocol, propionibacteria were recovered in the human faeces at concentrations between $10^{6}$ and $10^{7} \mathrm{CFU}$ per $\mathrm{g}$ of faeces, while they were undetectable before treatment. The maximal faecal concentrations of acetate and propionate were $45.7 \mathrm{mM}$ and $11.3 \mathrm{mM}$, respectively, after this treatment, versus $18.3 \mathrm{mM}$ and $4.9 \mathrm{mM}$ before the treatment. Here, acetate concentration in DMEM culture SN ranged from 9 to $16 \mathrm{mM}$ and propionate concentration from 26 to $40 \mathrm{mM}$, depending on the propionibacterial strain used. In parallel, propionibacterial population reached $15.10^{6}$ to $75.10^{6}$ CFU.ml (data not shown). Thus, propionibacterial population and SCFAs concentrations were in the same range in both in vitro and in vivo experiments. Based on SCFA concentrations in vitro and in vivo, it is not unlikely that propionibacteria can favor apoptosis induction of tumor cells via the local production of SCFA. Moreover, in vivo, carbohydrates that have not been resorbed in the small intestine, are delivered to the colon where they are fermented by the anaerobic microflora to SCFA. ${ }^{6}$ Thus, the concentration of total SCFA (acetate+butyrate+propionate) has been reported to reach values of $100 \mathrm{mM}$ in the lumen of the hind gut. ${ }^{6}$ Butyrate, the most studied SCFA, has been found to stimulate proliferation of normal crypt cells, yet apoptosis of colorectal cancer cells. ${ }^{6}$ Moreover, butyrate has been reported to induce colorectal carcinoma cell apoptosis via a process that involves cell cycle arrest in the G0-G1 and G2-M phases, ${ }^{7}$ inhibition of a histone deactylase, activation of a DEVD-caspase, cleavage of the cyclin-dependent kinase inhibitor p21 Waf1/Cip1,34 $\mathrm{Bcl}-2$ protection ${ }^{42,43}$ and DNA fragmentation. ${ }^{5}$ This led to the general proposal that SCFA could play a role in digestive cancer prevention. Indeed, high fiber diet which favors butyrate production, reduces the expression of $\mathrm{Bcl}-2$, decreases the rate of aberrant crypt foci in rats, and also reduces the incidence of human colorectal cancer, ${ }^{44,45,46}$ Thus, our results extend the hypothesis that SCFA might have a prophylactic action on colon cancer ${ }^{8}$ to propionate and acetate. Considering that dairy propionibacteria are known to adhere to human ileal glycoproteins, ${ }^{47,48}$ to Caco-2 cells in vitro (our unpublished data), as well as to the intestinal mucus, ${ }^{49}$ they might serve for the local delivery of SCFA at the colonocyte level. Dairy propionibacteria, including $P$. acidipropioninici and $P$. freudenreichii are generally recognized as safe bacteria and have already been used as human probiotics, mainly due to their bifidogenic effect. ${ }^{41}$ Future clinical and/or epidemiological studies will determine whether these probiotics will also reduce the incidence of colon cancer.

\section{Material and Methods}

\section{Chemicals}

When not specified, chemicals were purchased from SIGMA, and protocols were those indicated by suppliers.

\section{Cell lines and culture conditions}

HT29 cells (a gift from Zweibaum A., INSERM U178, Villejuif, France), Caco2 cells (a gift from Kaeffer B., INRA UR1026, Nantes, France), HeLa cell clones stably transfected with the pcDNA3 vector only, Bcl2, or vMIA ${ }^{33}$ (a gift from Goldmacher V., ImmunoGen, Inc., Cambridge, MA) were cultured in DMEM medium supplemented with $10 \%$ heat inactivated-fetal calf serum and antibiotics at $37^{\circ} \mathrm{C}$ under $5 \% \mathrm{CO}_{2}$.

\section{Bacterial cultures and supernatants preparation}

Propionibacterium acidipropionici strain CNRZ80 (Centre National de Recherches Zootechniques, Jouy-en-Josas, France), P. freudenreichii subsp. freudenreichii strain ITG18 (Institut Technique du Gruyère, Rennes, France) and $P$. freudenreichii subsp. shermanii strain SI41 (Standa-Industrie, Caen, France) were routinely cultivated on a modified yeast extract-lactate (YEL) medium and stored at $-80^{\circ} \mathrm{C}$ in the same medium supplemented with $15 \%$ glycerol. Such cultures were used to inoculate DMEM medium supplemented with $10 \%$ heat inactivated-fetal calf serum, but without antibiotics. After growth, bacterial DMEM supernatants (SN) were prepared by centrifugation $\left(12000 \mathrm{~g}, 4^{\circ} \mathrm{C}, 15 \mathrm{~min}\right.$ ) and $0.22 \mu \mathrm{m}$-filter-sterilized. All bacterial cultures were less than four passages from the collection stock.

\section{Lyophilization of bacterial supernatant SN-CNRZ80}

To lower the amount of SCFA in SN, lyophilization was performed as follows. A CNRZ80 DMEM culture supernatant was brought to $\mathrm{pH} 2.5$ using $2 \mathrm{~N} \mathrm{HCl}$ in order to protonate SCFA before freezing at $-80^{\circ} \mathrm{C}$. The resulting product was lyophilized and kept 3 days under vacuum $\left(0.05 \mathrm{mbar}, 10^{\circ} \mathrm{C}\right)$ to favor evaporation of volatile compounds. Bidistilled water was then added up to the initial volume and $2 \mathrm{~N}$ $\mathrm{NaOH}$ used to adjust the $\mathrm{pH}$ to its initial value $(\mathrm{pH} 5.5)$. The reconstituted supernatant was $0.22 \mu \mathrm{m}$-filter sterilized, and its SCFA content was analyzed by chromatography.

\section{Chromatographic analysis}

Organic acids were analyzed by high-performance liquid chromatography (HPLC, Gold, Beckman, USA) using UV detection at $210 \mathrm{~nm}$. The anion exchange column $\left(6 \times 300 \mathrm{~mm}\right.$, Aminex $\left.A_{6}\right)$ was operated at RT with $\mathrm{H}_{2} \mathrm{SO}_{4} 0.01 \mathrm{~N}(0.5 \mathrm{ml} / \mathrm{min})$ as eluent. Standard solutions of lactic acid, acetic acid, propionic acid and butyric acid of known concentrations were used for column calibration. 


\section{Cell treatment and viability monitoring}

HT29 and Caco2 cells were plated onto flat-bottom 24-well culture plates at $1.10^{5}$ cells/well. When cells reached $75 \%$ confluence, the medium was replaced with fresh medium containing SN-CNRZ80, SN-ITG18, acetate and propionate. For co-cultures, the medium was replaced with DMEM inoculated with each of the three propionibacteria tested. Heatinactivated bacteria $\left(80^{\circ} \mathrm{C}, 15 \mathrm{~min}\right)$ were also inoculated as a comparison. Three wells per plate were kept as controls and received unmodified DMEM. After 0, 6, 12, 24, 28 and 96 h of contact, cells were trypsinized, dissociated with DMEM and diluted in a $0.4 \%$ buffered saline trypan blue solution. Live cells were counted under a Zeiss microscope using a Malassez counting chamber, and counts were expressed as a percentage of the mean obtained for the three untreated wells.

\section{Fluorescence microscopy}

$0.5 .10^{6}$ treated and untreated HT29 and Caco2 cells were trypsinized and resuspended in fresh DMEM supplemented with $2 \mu \mathrm{M}$ of the DNAintercalating Hoechst $\mathrm{H} 33342$ as previously described. ${ }^{12}$ After a 10 min incubation at $37^{\circ} \mathrm{C}$, cells were examined with a fluorescence microscope (Leica, DMRB type, filter, $340-380 \mathrm{~nm} ; 430 \mathrm{~nm}$ ).

\section{Western blotting}

$5.10^{6}$ HT29 and Caco2 cells were trypsinized and lyzed in SDSsample buffer by sonication, followed by boiling for $5 \mathrm{~min}$. The protein extracts were separated on $13 \%$ polyacrylamide gels. Proteins were then transferred onto nitrocellulose membranes using a semi-dry system. Caspase-3 subunit was detected using a cleaved caspase-3 rabbit monoclonal antibody (D175, Cell Signaling Technology, MA, USA) and alkaline phosphatase-conjugated goat IgGs directed against rabbit IgGs as primary and secondary antibodies, respectively. The substrate used for detection was 5-bromo-4-chloro-3-indolyl phosphate/Nitro blue tetrazolium.

\section{Cytofluorimetric analysis of apoptosis}

0.3.10 $0^{6}$ HT29, HeLa-Neo, HeLa-Bcl-2, and HeLa-Bcl-2 cells cultured overnight at $37^{\circ} \mathrm{C}$ with the indicated doses of bacterial SN, propionate and/or acetate. Trypsinized cells were labeled with $40 \mathrm{nM} 3-3^{\prime}$ dihexyloxacarbocyanineiodide $\left(\mathrm{DiOC}_{(6)} 3\right.$; Molecular Probes, Eugene, $\mathrm{OR}, \mathrm{USA}$ ) and $2 \mu \mathrm{M}$ dihydroethidine (HE; Molecular Probes, Eugene, OR, USA) for 10 min at $37^{\circ} \mathrm{C}$. Cells were then analyzed by cytofluorimetry (FACSVantage, Becton Dickinson) as previously described. ${ }^{49}$

\section{Spectrophotometric determination of mitochondrial matrix swelling}

Mouse liver mitochondria were purified and resuspended in a buffer containing $200 \mathrm{mM}$ sucrose, $10 \mathrm{mM}$ Tris-MOPS (pH 7.4), $5 \mathrm{mM}$ Trissuccinate, $1 \mathrm{mM}$ Tris-phosphate, $2 \mu \mathrm{M}$ rotenone, and $10 \mu \mathrm{M}$ EGTA. Large amplitude mitochondrial swelling was measured spectroscopically by the loss of absorbance at $540 \mathrm{~nm}$, as described. ${ }^{50}$ When indicated, $10 \mu \mathrm{M}$ cyclosporin A were added to the mitochondria (110 $\mu \mathrm{g}$ proteins $/ \mathrm{ml}$ ) prior to the addition of DMEM containing $10 \%$ fetal calf serum as a negative control, $100 \mu \mathrm{M}$ calcium as a $100 \%$ control, or the indicated dose of bacterial supernatants, propionate or acetate, and absorbance was recorded for $20 \mathrm{~min}$.

\section{ANT liposomes}

ANT was purified from rat heart mitochondria ${ }^{11}$ and was reconstituted in phosphatidylcholine/cardiolipin $(45: 1, w: w)$ liposomes by $a$ surfactant dialysis method. ${ }^{11,21}$ ANT-proteoliposomes were sonicated in the presence of $1 \mathrm{mM} 4-\mathrm{MUP}$ and $10 \mathrm{mM} \mathrm{KCl}(50 \mathrm{~W}, 22 \mathrm{sec}$, Branson sonifier 250) on ice as previously described. ${ }^{16}$ Then, liposomes were separated on Sephadex G-25 columns (PD-10, Pharmacia) from unencapsulated products. $25 \mu$-aliquots of liposomes were mixed with $25 \mu \mathrm{l}$ of various concentrations of the proapoptotic inducer atractyloside $(200 \mu \mathrm{M})$ or SCFA dissolved in $10 \mathrm{mM}$ Hepes, $125 \mathrm{mM}$ saccharose ( $\mathrm{pH} 7.4$ ), diluted to $3 \mathrm{ml}$ and incubated for $1 \mathrm{~h}$ at RT. ATP and ADP were added to the liposomes $30 \mathrm{~min}$ prior to liposome treatment. After addition of $10 \mu$-alkaline phosphatase (5 $\mathrm{U} /$ $\mathrm{ml}$, Boehringer Mannheim) diluted in liposomes buffer+0.5 mM MgCl , samples were incubated for $15 \mathrm{~min}$ at $37^{\circ} \mathrm{C}$ under constant agitation and the enzymatic conversion of 4-MUP in 4-MU was stopped by addition of $150 \mu$ l Stop buffer (10 mM Hepes $-\mathrm{NaOH}, 200 \mathrm{mM}$ EDTA, $\mathrm{pH}$ 10). The 4-MU fluorescence was quantified using a Perkin Elmer spectrofluorimeter. Atractyloside, a pro-apoptotic permeability transition inducer, was used in each experiment as a standard to determine the $100 \%$ response. The percentage of 4-MUP release induced by SCFA was calculated as following: [(fluorescence of liposomes treated by SCFA-fluorescence of untreated liposomes)/(fluorescence of liposomes treated by atractyloside-fluorescence of untreated liposomes)] $\times 100$.

\section{Acknowledgements}

The authors want to thank Standa Industrie for financial support and for a constant interest. MB Maillard is acknowledged for her technical assistance in HPLC analysis, and P Legrand for access to his laboratory facilities. V Goldmacher is acknowledged for the generous gift of HeLa cell clones stably transfected with the pcDNA3 vector only, Bcl-2, or VMIA and the critical reading of the manuscript. This work has been supported by a special grant from the Ligue Nationale contre le Cancer as well as by grants from ANRS (to G Kroemer), FRM (to G Kroemer and C Brenner), ARC to C Brenner) and the European Commission (QLG1-1999-00739 to $G$ Kroemer). A-S Belzacq receives a fellowship from ARC and D Haouzi from the Ligue Nationale contre le Cancer.

\section{References}

1. Willet WN (2000) Diet and Cancer. The Oncologist 5: 393-404

2. Fuller R (1989) Probiotics in man and animals. J. Appl. Bacteriol. 66: 365-378

3. Britz T and Steyn P (1979) Volatile fatty acid production by the dairy and clinical propionibacteria and related coryneforms. Phytophylactica 11: 111-115

4. Hague A, Singh B and Paraskeva C (1997) Butyrate acts as a survival factor for colonic epithelial cells: further fuel for the in vivo versus in vitro debate. Gastroenterology 112: 1036-1040

5. Hague A, Elder DJ, Hicks DJ and Paraskeva C (1995) Apoptosis in colorectal tumour cells: induction by the short chain fatty acids butyrate, propionate and acetate and by the bile salt deoxycholate. Int. J. Cancer 60: 400-406

6. Scheppach W, Bartram HP and Richter F (1995) Role of short-chain fatty acids in the prevention of colorectal cancer. Eur. J. Cancer 31A: 1077-1080

7. Heerdt BG, Houston MA and Augenlicht LH (1997) Short-chain fatty acidinitiated cell cycle arrest and apoptosis of colonic epithelial cells is linked to mitochondrial function. Cell Growth Differ. 8: 523-532

8. Marchetti C, Migliorati G, Moraca R, Riccardi C, Nicoletti I, Fabiani R, Mastrandrea V and Morozzi G (1997) Deoxycholic acid and SCFA-induced apoptosis in the human tumor cell-line HT-29 and possible mechanisms. Cancer Lett. 14: $97-99$

9. Zoratti M and Szabo I (1995) The mitochondrial permeability transition. Biochim. Biophys. Acta. 1241: 139-176

10. Marzo I, Brenner C, Zamzami N, Susin SA, Beutner G, Brdiczka D, Rémy R, Xie ZH, Reed JC and Kroemer G (1998a) The permeability transition pore complex: a target for apoptosis regulation by caspases and Bcl-2-related proteins. J. Exp. Med. 187: 1261-1271 
11. Marzo I, Brenner C, Zamzami N, Jürgensmeier JM, Susin SA, Vieira HLA, Prévost MC, Xie Z, Matsuyama S, Reed JC and Kroemer G (1998b) Bax and Adenine Nucleotide Translocator Cooperate in the Mitochondrial Control of Apoptosis. Science 281: 2027-2031

12. JacototE, Ravagnan L, Loeffler M, Ferri KF, Vieira HL, Zamzami N, Costantini $P$, Druillennec S, Hoebeke J, Briand JP, Irinopoulou T, Daugas E, Susin SA, Cointe D, Xie ZH, Reed JC, Roques BP and Kroemer G (2000) The HIV-1 viral protein R induces apoptosis via a direct effect on the mitochondrial permeability transition pore. J. Exp. Med. 191: 33-46

13. Jacotot E, Ferri KF, El Hamel C, Brenner C, Druillennec S, Hoebeke J, Rustin P, Metivier D, Lenoir C, Geuskens M, Vieira HL, Loeffler M, Belzacq AS, Briand JP, Zamzami N, Edelman L, Xie ZH, Reed JC, Roques BP and Kroemer G (2001)Control of Mitochondrial Membrane Permeabilization by Adenine Nucleotide Translocator Interacting with HIV-1 Viral Protein R and Bcl-2. J. Exp. Med. 193: 509-520

14. Decaudin D, Marzo II, Brenner C and Kroemer G (1998) Mitochondria in chemotherapy-induced apoptosis: A prospective novel target of cancer therapy. Int. J. Oncol. 12: 141-152

15. Costantini $P$, Jacotot E, Decaudin D and Kroemer G (2000) Mitochondrion as a novel target of anticancer chemotherapy. J. Natl. Cancer Inst. 92: 1042-1053

16. Belzacq AS, JacototE, Vieira HL, Misro D, Granville DJ, XieZ, Reed JC, Kroemer $G$ and Brenner $C$ (2001) Apoptosis induction by the photosensitizer verteporfin: identification of mitochondrial adenine nucleotide translocator as a critical target. Cancer Res. 61: 1260-1264

17. De Pablo M, Susin SA, Jacotot E, Larochette N, Costantini P, Ravagnan L, Zamzami N and Kroemer G (1999) Palmitate induces apoptosis via a direct effect on mitochondria. Apoptosis 4: $81-87$

18. Rippo MR, Malisan F, Ravagnan L, Tomassini B, Condo I, Costantini P, Susin SA, Rufini A, Todaro M, Kroemer G and Testi R (2000) GD3 ganglioside directly targets mitochondria in a Bcl-2-controlled fashion. Faseb. J. 14: 2047-2054

19. Kroemer G and Reed JC (2000) Mitochondrial control of cell death. Nat. Med. 6 : 513-519

20. Vieira HL, Haouzi D, El Hamel C, Belzacq AS, Brenner C and Kroemer G (2000) Mitochondrial membrane permeabilization during apoptosis. Impact of the adenine nucleotide translocator. Cell Death Differ. 7: 1146-1154

21. Brenner C, Cadiou H, Vieira HL, Zamzami N, Marzo I, Xie Z, Leber B, Andrews D, Duclohier H, Reed JC and Kroemer G (2000) Bcl-2 and Bax regulate the channel activity of the mitochondrial adenine nucleotide translocator. Oncogene 19: $329-336$

22. Shimizu S, Narita M and Tsujimoto $Y$ (1999) Bcl-2 family proteins regulate the release of apoptogenic cytochrome $c$ by the mitochondrial channel VDAC. Nature 399: 483-487

23. Vogelstein B, Lane D and Levine AJ (2000) Surfing the p53 network. Nature 16: $307-310$

24. Fulda S, Susin SA, Kroemer G and Debatin KM (1998a) Molecular ordering of apoptosis induced by anticancer drugs in neuroblastoma cells. Cancer Res. 58: 4453-4460

25. Fulda S, Scaffidi C, Susin SA, Krammer PH, Kroemer G, Peter ME and Debatin KM (1998b) Activation of mitochondria and release of mitochondrial apoptogenic factors by betulinic acid. J. Biol. Chem. 273: 33942-33948

26. Ravagnan L, Marzo I, Costantini P, Susin SA, Zamzami N, Petit PX, Hirsch F, Goulbern M, Poupon MF, Miccoli L, Xie Z, Reed JC and Kroemer G (1999) Lonidamine triggers apoptosis via a direct, Bcl-2-inhibited effect on the mitochondrial permeability transition pore. Oncogene 18: 2537-2546

27. Larochette N, Decaudin D, Jacotot E, Brenner C, Marzo I, Susin SA, Zamzami N, Xie Z, Reed J and Kroemer G (1999) Arsenite induces apoptosis via a direct effect on the mitochondrial permeability transition pore. Exp. Cell Res. 249: 413-421

28. Marchetti P, Zamzami N, Joseph B, Schraen-Maschke S, Mereau-Richard C Costantini P, Metivier D, Susin SA, Kroemer G and Formstecher P (1999) The novel retinoid 6-[3-(1-adamantyl)-4-hydroxyphenyl]-2-naphtalene carboxylic acid can trigger apoptosis through a mitochondrial pathway independent of the nucleus. Cancer Res. 59: 6257-6266

29. Genini D, Adachi S, Chao Q, Rose DW, Carrera CJ, Cottam HB, Carson DA and Leoni LM (2000) Deoxyyadenosine analogs induce programmed cell death in chronic lymphocytic leukemia cells by damaging the DNA and by directly affecting the mitochondria. Blood 96: $3537-3543$
30. Watabe M, Machida K and Osada H (2000) MT-21 is a synthetic apoptosis inducer that directly induces cytochrome $\mathrm{c}$ release from mitochondria. Cancer Re. 60: 5214-5222

31. Jan G, Leverrier P, Pichereau V and Boyaval P (2001) Changes in protein synthesis and morphology during acid adaptation of Propionibacterium freudenreichii. Appl. Environ. Microbiol. 67: 2029-2036

32. Jan G, Rouault A and Maubois J (2000) Acid stress susceptibility and acid adaptation of Propionibacterium freudenreichii subsp. shermanii. Lait 80: $325-$ 336

33. Goldmacher VS, Bartle LM, Skaletskaya A, Dionne CA, Kedersha NL, Vater CA, Han J, Lutz RJ, Watanabe S, McFarland ED, Kieff ED, Mocarski ES and Chittenden T (1999) A cytomegalovirus-encoded mitochondria-localized inhibitor of apoptosis structurally unrelated to Bcl-2. Proc. Natl. Acad. Sci. USA 96: 12536-12541

34. Chai F, Evdokiou A, Young GP and Zalewski PD (2000) Involvement of p21(Waf1/Cip1) and its cleavage by DEVD-caspase during apoptosis of colorectal cancer cells induced by butyrate. Carcinogenesis 21: 7-14

35. Schonfeld P and Bohnensack R (1997) Fatty acid-promoted mitochondrial permeability transition by membrane depolarization and binding to the ADP/ATP carrier. FEBS Lett. 420: 167-170

36. Schonfeld P, Jezek P, Belyaeva EA, Borecky J, Slyshenkov VS, Wieckowski MR and Wojtczak L (1996) Photomodification of mitochondrial proteins by azido fatty acids and its effect on mitochondrial energetics. Further evidence for the role of the ADP/ATP carrier in fatty-acid-mediated uncoupling. Eur. J. Biochem. 240: $387-393$

37. Starkov AA, Markova OV, Mokhova EN, Arrigoni-Martelli E, Battelli D and Bobyleva VA (1993) The protective effect of cyclosporine A, carnitine, and $\mathrm{Mg}^{2+}$ with ADP during calcium ${ }^{2+}$-dependent permeabilization of mitochondria by fatty acids and activation of NADH oxidation by an external pathway. Biochemistry 58 : $1266-1275$

38. Wieckowski MR and Wojtczak L (1998) Fatty acid-induced uncoupling of oxidative phosphorylation is partly due to opening of the mitochondrial permeability transition pore. FEBS Lett. 423: 339-342

39. Von Engelhardt W, Burmester M, Hansen K, Becker G and Rechkemmer G (1993) Effects of amiloride and ouabain on short-chain fatty acid transport in guinea pig intestine. J. Physiol. (London) 460: 455-466

40. Chen YL, Yu CK and Lei HY (1999) Propionibacterium acnes induces acute TNF alpha-mediated apoptosis of hepatocytes followed by inflammatory T-cellmediated granulomatous hepatitis in mice. J. Biomed. Sci. 6: 349-356

41. Bouglé D, Roland F, Lebeurrier F and Arhan P (1999) Effect of propionibacteria supplementation on fecal bifidobacteria and segmental colonic transit time in healthy human subjects. Scand. J. Gastroenterol. 2: 145-148

42. Hague A, Diaz GD, Hicks D, Krajewski S, Reed JC and Paraskeva C (1997) bcl-2 and bak may play a pivotal role in sodium butyrate-induced apoptosis in colonic epithelial cells; however overexpression of bcl-2 does not protect against bakmediated apoptosis. Int. J. Cancer 72: 898-905

43. Csordas A and KoflerR(1999)Apoptosis induced by the histone deacetylase inhibito sodium butyrate in human leukemic lymphoblasts. FASEB J. 13: 1991-2001

44. Bingham SA (1990) Mechanisms and experimental and epidemiological evidence relating dietary fibre (non-starch polysaccharides) and starch to protection against large bowel cancer. Proc. Nutr. Soc., 49: 153-171

45. Avivi-Green C, Polak-Charcon S, Madar Z and Schwartz B (2000) Apoptosis cascade proteins are regulated in vivo by high intracolonic butyrate concentration: correlation with colon cancer inhibition. Oncol. Res., 12: 83-95

46. Perrin P,Pierre F, Patry Y, Champ M, Berreur M, Pradal G, BornetF, Meflah Kand Menanteau J (2001) Only fibres promoting a stable butyrate producing colonic ecosystem decrease the rate of aberrant crypt foci in rats. Gut 48: 53-61

47. Tuomola EM, Ouwehand AC and Salminen SJ (2000) Chemical, physical and enzymatic pre-treatments of probiotic lactobacilli alter their adhesion to human intestinal mucus glycoproteins. Int. J. Food Microbiol. 60: 75-81

48. Tuomola EM, Ouwehand AC and Salminen SJ (1999) Human ileostomy glycoproteins as a model for small intestinal mucus to investigate adhesion of probiotics. Lett. Appl. Microbiol. 28: 159-163 
49. Ouwehand AC, Tuomola EM, Tolkko S and Salminen S (2001) Assessment of adhesion properties of novel probiotic strains to human intestinal mucus. Int. J. Food Microbiol. 64: 119-126

50. Zamzami N, Susin SA, Marchetti P, Hirsch T, Gómez-Monterrey I, Castedo M and Kroemer G (1996) Mitochondrial control of nuclear aptotosis. J. Exp. Med. 183: $1533-1544$
51. Costantini P, Belzacq AS, Vieira HL, Larochette N, de Pablo MA, Zamzami N, Susin SA, Brenner C and Kroemer G (2000) Oxidation of a critical thiol residue of the adenine nucleotide translocator enforces Bcl-2-independent permeability transition pore opening and apoptosis. Oncogene 19: 307-314 